\title{
Preservice elementary teachers' willingness to specialize in science and views on evolution
}

\author{
Ronald S. Hermann*
}

\begin{abstract}
Background: Acceptance and understanding of evolutionary ideas remains low in the United States despite renewed science education standards, nearly unanimous acceptance among scientists, and decades of research on the teaching and learning of evolution. Early exposure to evolutionary concepts may be one way to reduce resistance to learning and accepting evolution. While there is emerging evidence that elementary students can learn and retain evolutionary ideas, there is also emerging evidence that elementary teachers may be unprepared to teach evolution. It may not be possible to train elementary teachers like their secondary counterparts who receive specialized training in science. This exploratory study was designed to determine if the 147 surveyed preservice elementary teachers (PETs) who are most willing to specialize in science maintain a greater understanding and acceptance of evolution. Such a relationship could have implications for teacher training and science instruction at elementary schools.

Results: As willingness to specialize in science increases so too does acceptance of evolution. For both measures, there was a monotonic increase with increasing willingness to specialize in science. There was a significant correlation ( $p=.047)$ between willingness to specialize in science and acceptance of evolution as measured by the MATE. There was not a significant correlation between willingness to specialize in science and understanding of evolution as measured by the CINS $(p=.21)$. The thirty-two PETs who are enthusiastically willing to specialize in science had the highest understanding and acceptance of evolution.

Conclusions: It may be possible to identify prospective elementary teachers that could assume roles as specialists simply by identifying PETs' willingness to specialize. Such students appear to enter elementary teacher preparation programs with the science background and enthusiasm for science required to be specialists without the need for much additional training. Thus, science teacher educators could help local elementary school principals identify graduating, and recently graduated, elementary teachers who are willing to specialize in science. Identified teachers could serve as specialists to work with their building and district colleagues to develop, among other topics, evolution related curricular materials and facilitate the implementation of those materials through co-teaching and peer coaching.
\end{abstract}

\section{Introduction}

The teaching of evolution in public schools in America and abroad has been a controversial issue since the 1925 Scopes Trial with legal challenges to teaching of evolution becoming increasingly more common since that famous trial (Hermann 2008). Anti-evolution views that lead to

*Correspondence: rhermann@towson.edu Department of Physics, Astronomy and Geosciences, Towson University, 8000 York Road, Towson, MD 21252, USA such legal cases are often first encountered by children at a young age, sometimes before their formal school science instruction (Hermann 2013). Thus, addressing antiscience messages and developing content knowledge of evolution among elementary-aged children may reduce the instances of students, parents, and politicians challenging the teaching of evolution in the classroom and in the courts. In this article I argue that although young children can develop anti-evolution views prior to learning about science in school, early evolution education 
experiences can help children better understand evolution. To do so, elementary teachers must possess an understanding of science and willingness to teach science to elementary level students. However, most elementary teachers complete a generalist model of training wherein they learn how to teach language arts, mathematics, science and social studies. Despite the generalist model, a subset of elementary teachers maintain a more specialized understanding of evolution (Hermann 2016). Identifying this population of preservice elementary teachers (PETs) may provide a way to identify elementary teachers that could serve as specialists to work with school and district colleagues to develop, among other topics, evolution related curricular materials and facilitate the implementation of those materials through co-teaching and peer-coaching.

In this exploratory study I sought to determine if PETs who are willing to specialize in science are also the same subset of teachers that maintain a high understanding and acceptance of evolution. The findings suggest that determining which students in a generalist elementary teacher education program are most willing to specialize in science may help identify PETs with a greater understanding and acceptance of evolution than their counterparts. These teachers may play a crucial role in mitigating the anti-evolution views young children may develop prior to learning science in a formal school setting.

\section{Background}

Evolutionary thought can be traced back to ideas of the ancient Greeks, Romans, and Chinese. Among many others, Jean-Baptiste Lamarck, Alfred Russel Wallace, and Charles Darwin advanced those ideas and proposed additional ideas to explain the diversity of life. These advances led to the development of more refined knowledge about natural selection, inheritance and variation, survival and reproduction, and adaptation (Gregory 2009). Our collective understanding of the diversity of life has been expanded upon greatly since the inception or those ideas and evolutionary ideas have become robust pillars of science to the point that not much in science makes sense except in the light of evolution (Dobzhansky 1973). Evolutionary theory provides scientists with the best explanation for the diversity and interrelatedness of species on earth and has been supported by empirical research across scientific fields ranging from anatomy to zoology. The scientific community overwhelmingly accepts evolution (Wiles 2014) to the point that not only science and science education organizations support the teaching of evolution, but religious organizations have also written position papers supporting the teaching of evolution (Sager 2008).

Regardless of the refinement to the theory of evolution over last several decades, and major advances in numerous fields of science that support, and are supported by the theory of evolution, many Americans do not believe in or accept the theory of evolution (Barone et al. 2014; Gallup 2014; Miller et al. 2006), do not understand the theory of evolution (Gregory 2009; Pew Research Center 2015), and do not want the theory of evolution taught in America's public schools (Gallup 2005). Moreover, some science teachers do not believe in the theory of evolution (Kim and Nehm 2011; Nehm and Schonfeld 2007), do not possess a strong understanding of the theory of evolution (Dodick et al. 2010; Kim and Nehm 2011; Nehm et al. 2009) and avoid teaching evolution or teach alternatives to evolution in America's public schools (Nehm and Schonfeld 2007; Nehm et al. 2009; Trani 2004).

How could it be that despite a firm foundation of scientific support for the theory of evolution, many Americans, including some teachers, do not understand evolution and/or maintain anti-evolution views? Classroom approaches to teaching evolution have fallen short of the level of rigor required for scientific literacy (Glaze and Goldston 2015). The teaching of evolution has not been effective at changing the hearts and minds of Americans. One way to address the low acceptance and understanding of evolution among the public may be to begin developing a firm scientific explanation of evolution during elementary level science instruction.

\section{Early evolution learning experiences}

Children are exposed to evolution during their elementary school years in the context of school, home, religious and media exposure (Donnelly and Akerson 2008). Thus, it is possible for children to develop anti-evolution sentiments prior to entering middle and high school when more class time is devoted to science instruction. The primary source of resistance to evolution instruction is related to what children know before their exposure to science (Bloom and Weisberg 2007). Further, resistance to scientific claims will persist into adulthood if those claims are contested in society and the resistance will be especially strong "if there is a nonscientific alternative that is rooted in common sense and championed by people who are thought of as reliable and trustworthy" (p. 997). The attitudes of parents, family members, clergy, the general public, and media may all contribute to the views young children develop about evolution. The way in which these groups talk about evolution is a critical element in facilitating the development of students' views on evolution. In a series of three experiments, Harris et al. (2006), sought to determine which entities (e.g. the Tooth Fairy, witches, flying pigs, germs, oxygen) children aged $4-8$ years thought existed and on what basis they made the claim for existence. Since direct 
observation of the entities examined is not possible, the researchers explored the role of other peoples' testimony about the entities. Harris et al. (2006) found that "children's beliefs vary with the level of testimonial support that they encounter, particularly from trusted sources such as parents" (p. 93). Moreover, in a series of studies among children aged 5-12 years, Evans (2000) concluded that 8-9 year-old children were likely to opt for creationist beliefs regardless of parental beliefs. However, children aged 10-12 years were able to provide evolutionary explanations, though they are more likely to be Lamarckian than Darwinian in nature. Evans (2001) study of 185 children and their mothers $(n=92)$ indicated that not until their early adolescent years (11-13 years) were children ready to abandon creationist theories and adopt naturalistic explanations that violated their strongly held beliefs. This literature suggests that children may have developed ideas about evolution prior to receiving instruction about evolution in a science classroom, and once creationist ideas develop it can be difficult introduce ideas more in line with scientifically accepted explanations.

Children who are exposed to anti-evolution messages may become adults who challenge the teaching of evolution as parents, teachers, school board members and political leaders. It is critically important that elementary students develop an understanding of science in order to evaluate anti-evolution messages when first encountered (Lombrozo et al. 2008). There is a promising line of research suggesting the elementary students can learn evolutionary principles and related ideas that are foundational to learning evolution.

Elementary level students have been the emphasis of several studies related to evolution education. Taken as a whole, this research indicates that elementary students are capable of learning evolutionary ideas when taught by highly trained instructors. Children 3-7 years old may develop a greater understanding of evolution by experiencing hands-on examples of life-span change when learning about within-species variation (Herrmann et al. 2013). Though creationist answers were found to be rare prior to instruction, evolutionist answers increased significantly after instruction among third grade students in Italy (Berti et al. 2015). Nadelson and Sinatra (2009) developed and taught lessons on speciation and adaptation to kindergarten and second grade students in the United States using inquiry and modeling. The students effectively communicated an understanding of similarities and differences of forearm structures. Fourth grade students were successfully taught "evolution readiness" which focused on adaptations, variation within species and inheritance of traits (Horowitz et al. 2013). French elementary level students have successfully learned concepts such as animal classification, interrelationship trees, and a comparison of natural selection to intelligent design (Chanet and Lusignan 2009). Students in grades K-4 were able to understand complex topics like natural selection and genetic drift (Campos and Sa-Pinito 2013). Children aged 5-8 years applied basic principles of natural selection 3 months after receiving instruction utilizing a 10-page picture book about fictional mammals with different trunk thicknesses resulting from a climatic change (Keleman et al. 2014).

Elementary teachers are well positioned to address misunderstandings and introduce scientifically accurate conceptions. However, elementary teachers are not likely to have a background in science (Fulp 2002) and they are less confident about teaching science compared to other core subjects (Cochran and Jones 1998). Elementary teachers with less science background and less confidence of teaching science may be more likely to avoid controversial subjects. Unfortunately, the outcome of many K-8 science education programs, even graduate school programs, may be teachers who are uncomfortable teaching evolution despite the fact that they may be perceived as being adequately prepared (Nadelson and Nadelson 2010). There is a growing body of work that has been conducted suggesting elementary teachers lack the content knowledge to effectively teach evolution. Canadian pre-service elementary teachers lacked an understanding of even the most basic concepts of evolution with almost a third planning to avoid or having reservations about teaching evolution (Asghar et al. 2007). Greek primary school instruction has been reported to be inadequate to introduce the theory of evolution of organisms to children (Prinou et al. 2011).

So, what can be done to improve elementary evolution instruction? Not surprisingly, almost every publication on the matter concludes with a call for additional evolution content coursework (Asghar et al. 2007; Nadelson and Nadelson 2010). It is often recommended that preservice teachers receive more instruction on evolution (Berkman and Plutzer 2012; Moore 2004). Appropriate changes to the structure and content of curriculum, along with changes to textbooks and appropriate programs for the training of teachers to introduce evolution in the primary grades, may result in reduced anti-intuitive notions of students (Prinou et al. 2011). However, Losh and Nzekwe (2011) explained that elementary school science curriculums are already crammed with many other subjects and suggested that improving elementary education programs is limited to adding additional topics and activities into elementary education science methods classes. Others have called for a course in evolution for secondary science education majors and incorporating evolutionary content into required science content for elementary 
majors (Fowler and Meisels 2010). Teachers would be better prepared to teach evolution if they took standalone classes in evolution, worked in active research laboratories, and took a university course providing them the opportunity to explore the relationship of their faith to evolutionary science (Berkman and Plutzer 2012). I have discussed elsewhere (Hermann 2013) why this may not be practical given the fact that teacher education programs are already crowded and there is rarely ample room for additional science content or methods coursework. So how can more science instruction be added to teacher preparation programs? It may be that the structure of elementary teacher preparation programs provides a significant barrier to PETs receiving high quality, and an acceptable quantity of, science and science pedagogy instruction.

\section{Structure of elementary education}

Gess-Newsome (1999) provided a description of five delivery models for elementary science instruction: classroom generalists, classroom science specialists, science support teams, departmentalization within grade levels and science specialists. Many elementary teacher preparation programs follow a generalist model with each teacher completing content and pedagogy courses in a multitude of subject matter such as reading, writing, mathematics, science, social studies, health, physical education and the fine arts (Gess-Newsome 1999). Research in this area has been limited, but the most recent study in 2013 indicated that only $10-16 \%$ of schools use science specialists either in place of, or in addition to, the regular classroom teacher (Banilower et al. 2013). A variety of different models are often used, even within a single district, though science specialists may devote more time to science instruction than generalists (Schwartz and GessNewsome 2008).

In contrast to elementary schools, secondary schools are structured such that middle or high school teachers are almost unanimously responsible for specializing in one subject area for which they must be knowledgeable and in the case of science, they often specialize or major in one sub-discipline of science, usually biology, chemistry, earth-space science, or physics. To that end, preservice education requirements are dramatically different for elementary and secondary teachers, with the latter completing much more science-specific coursework. For example, $40 \%$ of K-5 teachers reported having had four or fewer semesters of college level science (Weiss et al. 2001). The discrepancy between elementary and secondary teacher coursework is an artifact of the teacher preparation programs designed to match the generalist model most commonly employed in elementary schools. While some elementary schools may utilize a science specialist model, many of those specialists were assigned to that position by their principal regardless of their university coursework (Schwartz and Gess-Newsome 2008). Thus, the structure of elementary teacher education programs is often designed to prepare elementary education majors for a position as a generalist rather than a specialist in one content area. As such, it is to be expected that elementary teachers generally possess less science content knowledge than their secondary counterparts. In many cases this may be less of an issue, as elementary teachers are not expected to teach science concepts at a level requiring a highly sophisticated understanding of the concept that is achieved through greater coursework. However, with socioscientific issues such as evolution, elementary teachers play a critical role in confronting misunderstandings and helping students to understand the difference between science and non-science. Young children with beliefs that run counter to evolution must come to understand why those ideas, while important, are not based in science and, therefore, not topics of school science instruction. Generalist teacher education programs may lack sufficient space for science content which could greatly hinder elementary teachers' willingness and ability to identify misconceptions, overturn those misconceptions and explain the difference between science and other ways of knowing about the world. Elementary teachers receive less university science instruction with $6 \%$ of elementary science teacher having not had any college science, $20 \%$ having had courses in one of three areas (life science, physical science or Earth science), $38 \%$ having had courses in 2 of the three areas and $36 \%$ had courses in all three areas (Banilower et al. 2013). Moreover, only $39 \%$ of elementary teachers feel very well prepared to teach science compared to $77 \%$ for mathematics and $81 \%$ for reading/language arts (Banilower et al. 2013).

While few studies have explored the differences between science specialists and generalists, the results indicate that science specialist instructional planning was better aligned with reform-based practices (Schwartz et al. 2000) and specialists devote more instructional time to science, have a better attitude toward science, and increased students state test achievement (Schwartz and Gess-Newsome 2008). Science specialists may receive more science instruction and science related pedagogical knowledge than their generalist counterparts. However, some PETs enrolled in generalist programs maintain a high understanding of evolution and are accepting of the theory (Hermann 2016). The question remains as to whether those PETs with high understanding and acceptance of evolution are the same teachers most willing to specialize in science. In this study, I explored whether PETs in a generalist program who would be more willing 
to specialize in science also possessed a greater content knowledge of natural selection and were more accepting of the theory of evolution. This line of research could help science educators identify PETs who possess a more specialized view of science topics like evolution who are enrolled in generalist elementary teacher education programs. In turn, these majors could play a role in providing enhanced science instruction of all topics, including evolution.

\section{Methods}

In this study I explored whether elementary education majors with more understanding and acceptance of evolution are also more willing to specialize in science. Put another way, I was interested in exploring whether PETs who are most willing to specialize in science content are also more accepting of evolution and maintain a stronger understanding of natural selection. I hypothesized that willingness to specialize in science may be correlated with acceptance of evolution and understanding of natural selection.

Preservice elementary teachers at a state university in the Mid-Atlantic region were invited to participate in a short, exploratory 35 -item survey. PETs were asked to participate in the exploratory study by the course instructor and were informed that the study was approved by the Institutional Review Board and was a voluntary study that had no impact on their standing in the course. PETs at the university complete a science and mathematics semester during which they complete up to three science courses and one science pedagogy course with a field placement at local elementary schools. PETs complete three science courses, only one of which, The Principles of Biology, includes the topic of evolution. The two other required science courses are a physical science class and a life science and an Earth space science course. Of these three science classes, only the biology contains direct instruction on evolution. The Earth Science provides minimal additional instruction on evolutionary ideas such as deep time and the history of Earth. The PETs were surveyed in the Earth science course. For all intents and purposes, PETs do not take any additional science coursework after this semester which occurs late in their 3 rd year or early in their 4th year of study.

It was requested that all students enrolled in the class complete the survey, but the survey was not required, and students could decline to complete the survey. Surveys were completed by 147 PETs who were currently enrolled in elementary science methods classes. This population is $93.7 \%$ female and $83.9 \%$ consider themselves white. The remaining PETs identify with the following ethnicities: African American or Black (4.6\%), Hispanic (4.0\%), unknown (3.4), two or more races (2.3\%), and Asian or Pacific Islander (1.7\%).

The survey contained three sections related to preference to specialize in a specific content area, understanding of natural selection and acceptance of evolution. The first section of the survey contained four questions which permitted participants to select their willingness to teach English Language Arts, Mathematics, Science and Social Studies on a 4-point scale including the following options: not at all willing, minimally willing, moderately willing, or enthusiastically willing. The PETs were enrolled in a program that provides a generalist training model in which they prepare to teach all four subjects. PETs were informed that the present generalist model at the university was not going to change and the survey was for research purposes only. This section also contained an item to determine the grade level they expected to teach upon graduation.

While the term evolution refers to a broad spectrum of ideas and processes, the elementary level next generation science standards are largely written around the principles of natural selection and align well with the five facts and three inferences about natural selection as described by Mayr (1982). As such, the teaching and learning of evolution is often highly focused on natural selection as is the focus of this study. The second section of the survey included the 10-item conceptual inventory of natural selection 2013 middle school version A (CINS-A) instrument which was modified by Evans and Anderson (2013) as a modification of the original CINS (Anderson et al. 2002). The CINS-A was selected for this study because it contains ten rather than twenty questions and is written at a level that may be more appropriate for this population of PETs. The CINS-A instrument returns a whole-number score between 0 and 10, and the higher score indicates a higher understanding of natural selection. In this study the reliability of the CINS-A was low (.313) which may be due to several factors including the low number of items the instrument contains. A low number of test items violates the assumption of tau-equivalence and will result in an underestimated reliability (Graham 2006). Since each of the ten items on the CINS-A is designed to measure a different concept; the instrument may be more heterogeneous than homogeneous. When alpha is low due to poor correlation between items then some items should be revised or discarded. One way to find them is to compute the correlation of each test item with the total score and delete the items with low correlation (Tavakol and Dennick 2011). However, all ten items of the CINS-A are significantly correlated to the total CINS-A scores and nine items were significantly correlated at the .01 level.

The third section of the survey contained the 20-item measure of acceptance of the theory of evolution 
(Rutledge and Warden 1999). The MATE instrument returns a whole-number score between 20 and 100, and the higher score indicates a higher level of acceptance of evolution. The reliability of the MATE was .932 which is well within the acceptable range.

\section{Results}

In this exploratory study I asked PETs how willing they would be to specialize in four different subject areas: (a) English language arts, (b) mathematics, (c) science, and (d) social studies (Table 1). PETs willing to specialize in science are also more willing to specialize in mathematics $(r=.37, p \leq .01)$. Likewise majors willing to specialize in English language arts were also more willing to specialize in social studies $(r=.35, p \leq .01)$. Among PETs most willing to teach mathematics there was a tendency to want to do so in higher grade levels $(r=.19, p=.02)$. There was no significant correlation between willingness to teach science and preference for teaching at a particular grade level.

Only 13 of the 147 PETs responded that they were not at all willing to specialize in science if provided the option, the lowest number for all four content areas. Thirty-two PETs responded that they were enthusiastically willing to teach science. Thirty-two of the PETs responded that they were not at all willing to teach social studies, the highest of the four content areas. The greatest number of PETs, forty-three, were enthusiastically willing to teach English language arts and only twenty-one were enthusiastically willing to teach social studies.

Sixty-six of the PETs expected to teach grades K-2 upon graduation and 72 expected to teach grades 3-5. Only six expected to teach grades 6-8 and the remaining three expected to teach pre-K.

There is a noticeable pattern of increased understanding of natural selection with increased willingness to specialize in science (Table 2). Preservice elementary teachers not willing at all to specialize in science maintained the lowest scores $(4.08 ; S D=1.38)$ on the CINS-A which has a maximum score of 10 . The CINSA scores increased with each level of willingness to specialize in science and among those enthusiastically

Table 1 Frequencies of majors' willingness to specialize in each of the four elementary subject areas

\begin{tabular}{lrrcc}
\hline Willingness to teach & ELA & Math & Science & Social studies \\
\hline Not at all willing & 14 & 22 & 13 & 32 \\
Minimally willing & 30 & 43 & 49 & 40 \\
Moderately willing & 60 & 45 & 53 & 54 \\
Enthusiastically willing & 43 & 37 & 32 & 21 \\
Total & 147 & 147 & 147 & 147 \\
\hline
\end{tabular}

Table 2 Elementary education majors' understanding of natural selection by willingness to specialize in science

\begin{tabular}{llll}
\hline $\begin{array}{l}\text { Willingness to specialize } \\
\text { in science }\end{array}$ & $\mathbf{n}$ & \multicolumn{2}{c}{ CINS } \\
\cline { 3 - 4 } & & Mean & SD \\
\hline Not willing at all & 13 & 4.08 & 1.38 \\
Minimally willing & 46 & 4.78 & 1.78 \\
Moderately willing & 51 & 4.72 & 1.73 \\
Enthusiastically willing & 32 & 5.00 & 1.83 \\
\hline
\end{tabular}

willing to specialize in science the score was highest (5.00; $S D=1.83$ ). As with acceptance of evolution those minimally willing to specialize in science scored slightly higher than those moderately willing to specialize in science, 4.78 compared to 4.72 . Understanding of natural selection is not significantly different between any of the willingness to specialize in science groups $\left(F_{3,137}=.870\right.$, $p=.46)$. Note that the increasing monotonic pattern was not found when comparing willingness to specialize in language arts, mathematics, or social studies with understanding of natural selection. There was not a significant correlation between willingness to specialize in science and understanding of evolution as measured by the CINS $(r=.11, p=.21)$.

Among this relatively small sample of 147 PETs, the average understanding of natural selection was 4.74/10. While the results of the CINS-A have not been reported as much as the original CINS, the CINS authors stated that undergraduates are expected to answer about 50\% of the questions correctly and their sample scored $46.4 \%$ correctly (Anderson et al. 2002), which is similar to the CINS-A results in this exploratory study (47.4\%). Figure 1 shows a monotonic, but not significant, increase in understanding of evolution with increased willingness to specialize science. There was the greatest variation in CINS-A scores among those who were not at all willing to specialize in science.

The CINS-A contained 10 questions that measured understanding of natural selection and each question addressed a specific concept. The PETs surveyed were most likely (73.2\%) to correctly answer the first question related to biotic potential. They were least likely $(9.8 \%)$ to correctly answer the sixth question related to the origin of variation. This question asked how different beaks first appear in finches. For this question, the PETs most frequently (74.1\%) selected a response stating the beak size and shape happened because of their need to be able to eat different kinds of food. Several other questions indicated a lack of understanding of critical concepts of natural selection among the PETs as a group. Question 9 regarding change in populations was answered correctly by $35.7 \%$ of the PETs with 


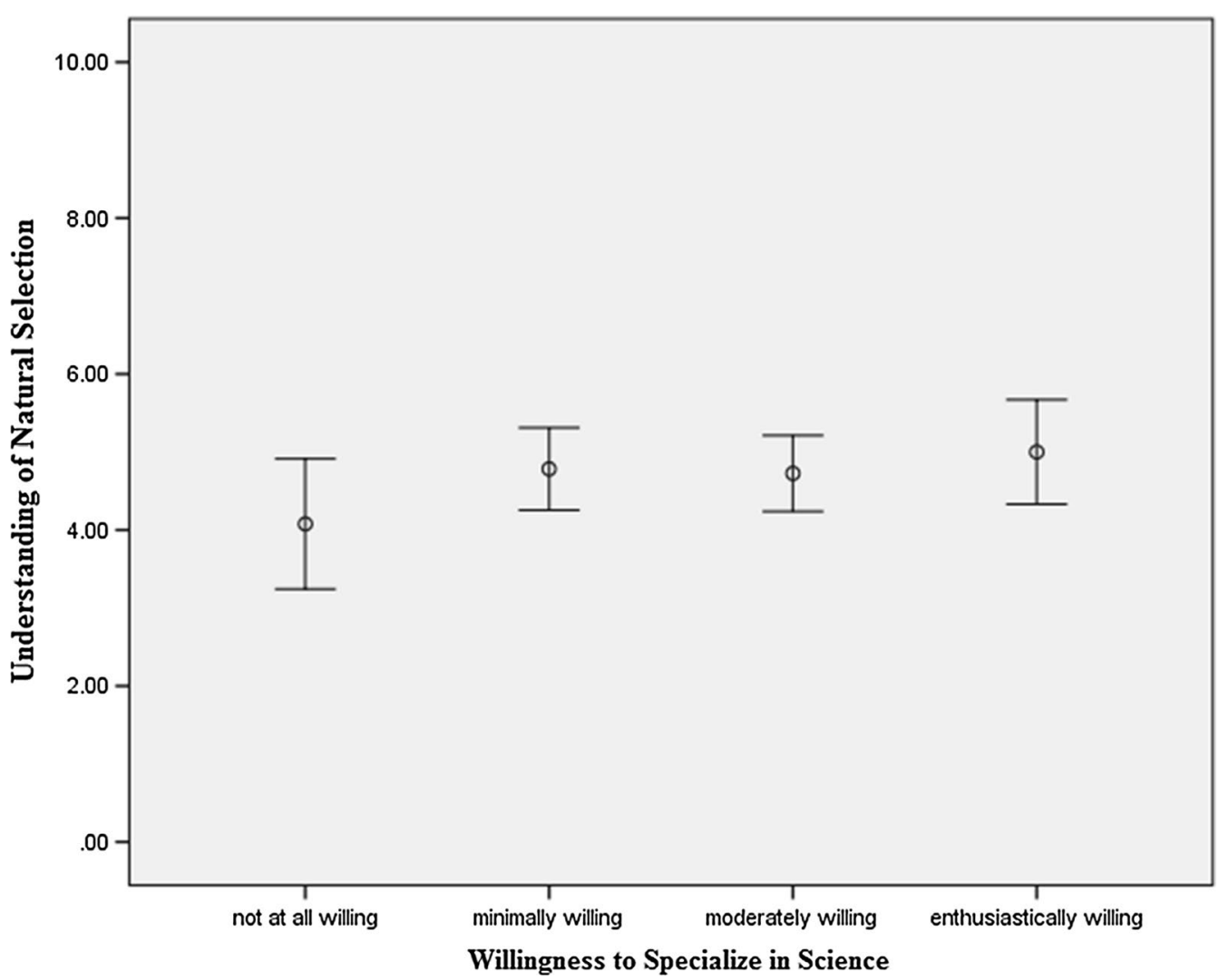

Fig. 1 Understanding of natural selection by willingness to specialize in science

incorrect answers fairly equally split among the three other options. Question 8 targeted the concept of differential survival. Only $36.6 \%$ of the PETs correctly answered this question, again with a fairly equal distribution across the other three answer options.

Among all 147 PETs surveyed, there was moderate acceptance (75.18/100) of evolution as measured by the MATE according to an acceptance level scale created by Rutledge and Sadler (2007). Table 3 indicates that, with the exception of thirteen PETs not willing at all to specialize in science, acceptance of evolution increases with willingness to teach science.

Table 3 Elementary education majors' acceptance of evolution by willingness to specialize in science

\begin{tabular}{lllll}
\hline $\begin{array}{l}\text { Willingness } \\
\text { to specialize in science }\end{array}$ & $\mathbf{n}$ & MATE & \multirow{2}{*}{ Acceptance level } \\
\cline { 2 - 4 } & & Mean & SD & \\
\hline Not willing at all & 13 & 74.00 & 14.28 & Moderate \\
Minimally willing & 49 & 73.06 & 11.98 & Moderate \\
Moderately willing & 53 & 74.66 & 12.87 & Moderate \\
Enthusiastically willing & 32 & 79.75 & 13.19 & High \\
\hline
\end{tabular}

Among those not at all willing to specialize in science there was moderate acceptance of evolution (74.00; $S D=14.28)$. PETs enthusiastically willing to specialize in science are categorized as having high acceptance of evolution (79.75; $\mathrm{SD}=13.19)$ related to the three other categories which maintain a moderate acceptance (Rutledge and Sadler 2007). Acceptance of evolution is not significantly different between any of the willingness to specialize in science groups $\left(F_{3,143}=1.882, p=.14\right)$. There was a weak $(r=.16)$, significant $(p=.047)$ between willingness to specialize in science and acceptance of evolution as measured by the MATE.

Interestingly, among those willing to specialize in mathematics, there was also a monotonic increase in acceptance of evolution. As willingness to specialize in math increased, so too did the acceptance of evolution with means of $70.28,74.49,76.29$, and 77.54, respectively. The positive, moderate significant correlation $(r=.37$, $p<.001)$ between willingness to specialize in science and willingness to specialize in math may account for this result. This pattern was not present for willingness to teach language arts or social studies.

Figure 2 shows a slight monotonic increase in average acceptance of evolution with increased willingness to 


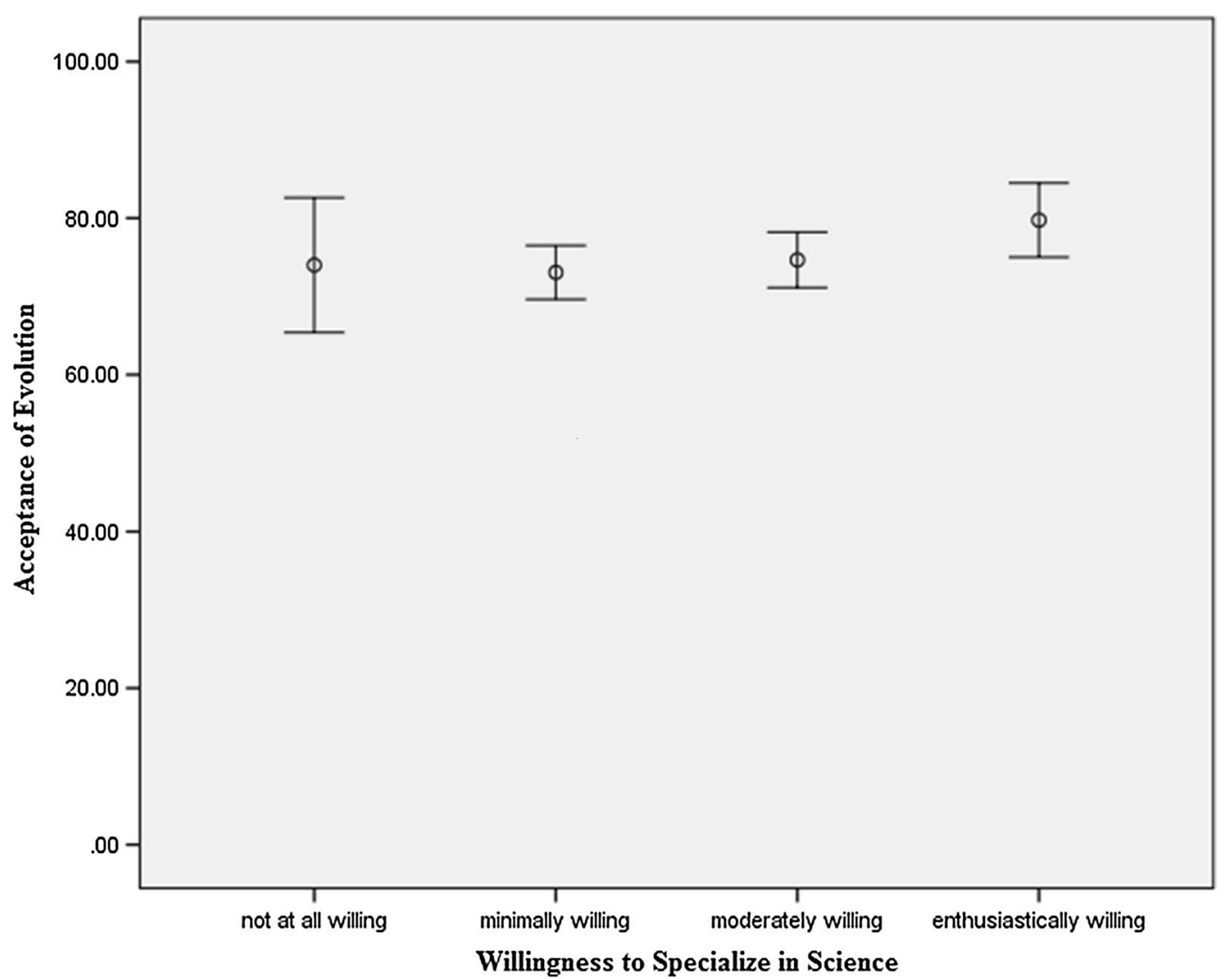

Fig. 2 Acceptance of evolution by willingness to specialize in science. Note the generally large range of variation among the nine elementary majors not at all willing to specialize in science

specialize in science and the wide range of acceptance held by those who selected each category of willingness to specialize in science. There is great variation in acceptance among the thirteen PETs who are not at all willing to teach science. Similarly, there are some PETs with a moderate acceptance of evolution who are enthusiastically willing to specialize in science. However, most of those enthusiastically willing to specialize in science have a high acceptance.

Across the entire sample of PETs there was a significant relationship between acceptance of evolution and understanding of natural selection $(r=.171, p=.043)$. Some studies suggest there is not a relationship between acceptance of evolution and understanding of evolution (Bishop and Anderson 1990; Demastes et al. 1995; Kahan 2015; Lord and Marino 1993; Sinatra et al. 2003), while others suggest such a relationship may exist (Deniz et al. 2008; Johnson and Peeples 1987; Rutledge and Warden 2000; Shtulman and Calabi 2012). This finding, though exploratory in nature, adds to the body of literature that suggests under some situations, for some populations, there may be a correlation between understanding or knowledge of evolution and its acceptance.

\section{Discussion}

Among preservice elementary teachers in a generalist teacher education program, a subset of PETs maintain a high acceptance and understanding of evolution (Hermann 2016). However, the extent to which these PETs are actually willing to focus more specifically on the teaching of science is unknown. This study explored the extent to which PETs willing to specialize in science at the elementary level are also the PETs who maintain the greatest acceptance and understanding of evolution. Such a group of teachers could serve specialist roles in elementary schools. In a recent study of elementary schools employing a specialist model it was determined that principals filled specialist positions to retain a classroom teacher in the face of declining enrollment rather than based on special knowledge or experience teaching science (Levy et al. 2016). The findings of this study could have implications for helping principals make staffing selections for elementary science specialist positions, in addition to enhancing the teaching of evolution at the elementary level.

The number of PETs who were not at all willing to specialize in science was the lowest, even lower than those 
not at all willing to specialize in English language arts, mathematics or social studies. Thus, despite reports that only $39 \%$ of elementary education majors feel very well prepared to teach science compared to $77 \%$ for mathematics (National Science Board 2014), 21.8\% of PETs in this sample felt prepared enough that they were enthusiastically willing to specialize science and another $36.1 \%$ were moderately willing to specialize in science if given the opportunity. Within this sample, nearly $58 \%$ of the PETs were moderately or enthusiastically willing to specialize in science. However, during data collection on a follow-up project I spoke with several colleagues at universities with programs to prepare PETs to specialize in science who indicated there is a much lower number of students actually enrolled in such programs suggesting a disconnect between a perceived willingness and actionable enrollment. The results of this study suggest that a more feasible way to enhance elementary level instruction may be to identify PETs who already possess a willingness to teach to science and a high acceptance and understanding of evolution rather than trying to (a) better prepare all elementary teachers, including those reluctant to learn or teach about science topics like evolution or (b) develop elementary teacher education programs that require majors to specialize in one content area.

\section{Understanding of natural selection}

In this study, PETs understanding of natural selection increased monotonically, but not significantly, as PETs reported more willingness to specialize in science. This is an important finding of this exploratory study as it suggests that a larger scale study with multiple measurements of understanding of natural selection and/or evolution is warranted.

Some PETs in a generalist teacher education program possess more specialized understanding of science content such as natural selection and those same PETs may also be willing to specialize in science. Further research is required to determine if there is a correlation between the two and the results of such a study could be beneficial for addressing evolution instruction at the elementary level in the future. The PETs in this exploratory study received minimal evolution instruction at the university level as a component of one course. They may, therefore, be recalling high school evolution instruction as well. This may account for some of the perceived misconceptions as the distractors for the CINS-A are misconceptions and careful consideration of the answer options is critical to selecting the most correct response. An increased understanding of natural selection does not, in and of itself, necessitate that these PETs will be more effective teachers of evolution than their counterparts. However, a lack of self-confidence in content knowledge leads teachers to deemphasize evolution (Rutledge and Mitchell 2002). Likewise, Berkman and Plutzer (2010) found a positive relationship between self-assessment of content mastery and more rigorous evolution instruction.

\section{Acceptance of evolution}

There is a moderate level of acceptance of the theory of evolution among the entire sample of 147 PETs. Among the thirteen PETs who were not willing at all to specialize in science there was great variation in their level of acceptance ranging from 56 (low acceptance) to 100 (very high acceptance). Three of the thirteen scored in the very high acceptance range (89-100) of the acceptance level scale created by Rutledge and Sadler (2007) with scores of 100, 94 and 90. The scores of three PETs raised the mean score to 74.00. Interestingly, the PETs who had the highest acceptance score (100) and third highest (90) scored among the highest in understanding of natural selection with 6/10, but the PET with a 94 in acceptance scored a $2 / 10$ in understanding of natural selection. This disparity may, in part, be explained by studies that have not found a relationship between understanding of evolution and acceptance of evolution (Deniz et al. 2008; Rutledge and Sadler 2011). Nevertheless, it is concerning that some individuals are highly accepting of evolutionary theory without a demonstrable understanding of evolutionary theory upon which to base their acceptance.

Beyond the variation in acceptance among those not at all willing to specialize in science, as willingness to specialize in science increases, acceptance of evolution also increases. Among the 32 PETs who are enthusiastically willing to specialize in science, acceptance of the theory of evolution was categorized as high according to the scale created by Rutledge and Sadler (2007).

The results of this study indicate that the 32 PETs who are enthusiastically willing to specialize in science also have the highest level of acceptance of the theory of evolution. This finding presents a promising avenue for elementary evolution education as it suggests that some of the PETs in generalist teacher education programs may be more willing to teach evolution at the elementary level than their peers. This subset of PETs may not fit the previous profile of existing literature which suggests elementary teachers are uncomfortable teaching evolution (Nadelson and Nadelson 2010), lack an understanding of the most basic concepts of evolution (Asghar et al. 2007), avoid teaching evolution (Asghar et al. 2007), and inadequate at introducing evolution to young children (Prinou et al. 2011). That is to say, this smaller sub-group of PETs may be in far less need of additional evolution content coursework often prescribed by researchers (Asghar et al. 2007; Berkman and Plutzer 2012; Moore 
2004; Nadelson and Nadelson 2010). Therefore, they may be in a prime position to serve as a science specialist as an inservice elementary teacher. In a study of mathematics specialists, a content area where such specialization is more common, approximately $41 \%$ of the 105 schools surveyed determined specialists by self-nomination with another $22 \%$ being determined by the principal (Gerreston et al. 2008). They also reported that $\sim 88 \%$ of 105 responding elementary school principals reported that specialist teachers become empowered and provide more effective classroom instruction. As such, this subset of PETs may be promising in filling specialist positions through self-nomination or the recognition of their principal and could provide more effective evolution education instruction.

\section{Limitations and implications for future research}

It remains to be seen whether PETs in a generalist program who are enthusiastically willing to specialize in science possess a greater understanding of natural selection and acceptance of evolution compared to PETs actually enrolled in a science specialist teacher education program. I have begun data collection to explore the similarities and differences between PETs in generalist and specialist teacher education programs. However, there are very few majors in specialist elementary teacher education programs and data collection is ongoing.

This is an exploratory study, but further research is required to determine the extent to which those who are enthusiastically willing to specialize in science address evolution differently, if at all, during elementary instruction as compared to their peers who identified as less willing to specialize in science.

Though there are documented issues with the MATE and CINS instruments (Ha et al. 2015; Nehm and Schonfeld 2008; Smith 2010; Wagler and Wagler 2013), they are nevertheless frequently used instruments in evolution education research. In this instance, the reliability of the CINS-A is very low, but since each item was found to be significantly correlated to the total score, this may just be due to the instrument only containing ten items. Additionally, the PETs surveyed may not have received instruction related to natural selection for a semester or two and the CINS-A may have served as more of a pretest than a posttest and Cronbach's alpha is generally lower on pretests.

The issues with the instruments was compounded by the relatively low sample size of 147 PETs, though this study served more as a proof of concept than a large-scale research study. Despite these limitations, the descriptive statistics indicate differences among PETs when grouping them by their willingness to specialize in science. Though this trend may not be significant with the current sample size and instrumentation, this line of exploration warrants further research with a larger sample and, possibly, different instruments.

\section{Conclusions}

Despite decades of research on the teaching and learning of evolution, there remains a great deal of misconceptions about evolution among the public and students of all levels (Gregory 2009; Rice et al. 2015). A misunderstanding of evolution may be the result of, or is at least compounded by, the omission or watering down of evolution topics or inclusion of nonscientific ideas like creationism or intelligent design (Berkman and Plutzer 2011; Moore 2008). As such, most students know very little about evolution and only retain what they need to pass exams but over time they often return back to their earlier ideas about evolution (Nehm and Schonfeld 2007). It should be clear that well prepared instruction on evolution topics should be a consistent theme of science instruction across all grade bands to effectively educate students of all ages about how evolution works, the supporting evidence for evolution, and why alternatives to evolution are not considered science. Of critical importance is the early teaching of evolution during the elementary school years as children begin hearing antievolution messages early in their life (Hermann 2011). Since understanding evolution may influence evolution acceptance (Nadelson and Sinatra 2009; Wiles 2014), providing elementary students with foundational knowledge about evolution at this time may help combat antievolution messages and non-scientific instruction.

While there is minimal research on elementary evolution instruction, what research there is suggests that elementary teachers are not well positioned to teach evolution. Elementary teachers may not be well prepared to teach evolution, accepting of evolution of understand evolutionary concepts at a sufficient level (Asghar et al. 2007; Fowler and Meisels 2010; Nadelson and Nadelson 2010). Completion of an evolution course has also been found to be a predictor of classroom time devoted to teaching evolution (Berkman et al. 2008; Donnelly and Boone 2007). Knowledge of evolution tends to increase with greater exposure to evolution (Kim and Nehm 2011; Moore et al. 2011). However, there is likely little room in generalist elementary education programs to include additional coursework and competition among disciplines for what space might be available. While one solution is to provide specialist elementary education programs, such programs are rare and those that do exist contain few enrolled students. 
Another solution is evident from this exploratory study. Some PETs in generalist programs, who are willing to specialize in science, also maintain greater levels of acceptance of evolution than their peers who are less willing to specialize in science. The results of this study suggest that by identifying PETs willing to specialize in science, we may also be able to identify PETs who possess a higher acceptance of evolution than their counterparts without any additional training or coursework. This population could serve as science specialists. Some elementary schools employ variations of the specialist model described by Gess-Newsome (1999). In a study on the use of mathematics specialists, a subject where the specialist model is more prevalent, principals reported selecting specialists based on: their students' test grades, self-nomination, by a discussion between the principal and teachers, and as a principal decision (Gerreston et al. 2008). Science specialists could develop curriculum, provide resources, offer professional development, deliver science instruction alone or in a co-teaching model, and serve as a coach or mentor to classroom generalists to enhance science instruction with such support resulting in higher quality science learning experiences for elementary children. (Schwartz and Gess-Newsome 2008). Thus, science teacher educators could help local elementary school principals identify graduating, and recently graduated, elementary teachers who are willing to specialize in science. Identified teachers could serve as specialists to work with their building and district colleagues to develop, among other topics, evolution related curricular materials and facilitate the implementation of those materials through co-teaching and peer coaching. While it may not be feasible to provide specialist science content training to all preservice elementary teachers, it may be possible to utilize those who are already willing to specialize in science as they may also possess a greater understanding and acceptance of science concepts like evolution.

\section{Abbreviations}

CINS: conceptual inventory of natural selection; MATE: measure of acceptance of the theory of evolution; PET: preservice elementary teacher.

\section{Authors' contributions \\ The author read and approved the final manuscript.}

\section{Competing interests}

The authors declare that they have no competing interests.

\section{Consent for publication}

Not applicable.

\section{Ethics approval and consent to participate}

The (University Name Withheld for Review) Institutional Review Board for the Protection of Human Subjects (IRB) approved this research as exempt from general Human Participants requirements according to 45 CFR 46.101 (b)(2). Exemption Number: 14-X016.

\section{Publisher's Note}

Springer Nature remains neutral with regard to jurisdictional claims in published maps and institutional affiliations.

Received: 23 February 2018 Accepted: 9 July 2018

Published online: 17 July 2018

\section{References}

Anderson DL, Fisher KM, Norman GJ. Development and evaluation of the conceptual inventory of natural selection. J Res Sci Teach. 2002;39:952-78.

Asghar A, Wiles JR, Alters B. Canadian pre-service elementary teachers' conceptions of biological evolution and evolution education. McGill J Educ. 2007:42:189-209.

Hermann RS. Evolution as a controversial issue: a review of instructional approaches. Sci Educ. 2008;17:1011-32.

Hermann RS. Breaking the cycle of continued evolution education controversy: on the need to strengthen elementary level teaching of evolution. Evol Educ Outreach. 2011;4:267-74.

Hermann RS. On the legal issues of teaching evolution in the public school. Am Biol Teach. 2013;75(8):538-42.

Hermann RS. Elementary education majors'views on evolution: a comparison of undergraduate majors understanding go natural selection and acceptance of evolution. Electron J Sci Educ. 2016;20(6):21-44.

Banilower ER, Smith PS, Weiss IR, Malzahn KA, Campbell KM, Weis AM. Report of the 2012 national survey of science and mathematics education. Chapel Hill: Horizon Research Inc.; 2013.

Barone LM, Petto AJ, Campbell BC. Predictors of evolution acceptance in a museum population. Evol Educ Outreach. 2014. https://doi.org/10.1186/ s12052-014-0023-2.

Berkman MB, Plutzer E. Evolution, creationism, and the battle to control America's classrooms. New York: Cambridge University Press; 2010.

Berkman MB, Plutzer E. Defeating creationism in the courtroom, but not in the classroom. Science. 2011;331:404-5.

Berkman MB, Plutzer E. An evolving controversy: the struggle to teach science in science classes. Am Educ. 2012;36(2):12-7, 20-3, 40.

Berkman MB, Pacheco JS, Plutzer E. Evolution and creationism in America's classrooms: a national portrait. PLoS Biol. 2008:6(5):e124.

Berti AE, Barbetta, Toneatti L. Third-graders' conceptions about the origin of species before and after instruction: an exploratory study. Int J Sci Math Educ. 2015. https://doi.org/10.1007/s10763-015-9679-5.

Bishop BA, Anderson CW. Student conceptions of natural selection and its role in evolution. J Res Sci Teach. 1990;27:415-27.

Bloom P, Weisberg DS. Childhood origins of adult resistance to science. Science. 2007:316:996-7.

Campos R, Sá-Pinto A. Early evolution of evolutionary thinking: teaching biological evolution in elementary schools. Evol Educ Outreach. 2013. https ://doi.org/10.1186/1936-6434-6-25.

Chanet R, Lusignan F. Teaching evolution in primary schools: an example in French classrooms. Evol Educ Outreach. 2009;2:136-40.

Cochran $\mathrm{K}$, Jones $\mathrm{L}$. The subject matter knowledge of preservice science teachers. In: Fraser BJ, Tobin KG, editors. International handbook of science education. Dordrecht: Kluwer Academic Publishers; 1998. p. 707-18.

Demastes SS, Settlage JS Jr, Good R. Students' conceptions of natural selection and its role in evolution: cases of replication and comparison. J Res Sci Teach. 1995;32:535-50.

Deniz H, Donnelly L, Yilmaz I. Exploring the factors related to acceptance of evolutionary theory among Turkish preservice biology teachers: toward a more informative conceptual ecology for biological evolution. J Res Sci Teach. 2008:45:420-43.

Dobzhansky T. Nothing in biology makes sense except in the light of evolution. Am Biol Teach. 1973;35:125-9.

Dodick J, Dayan A, Orion N. Philosophical approaches of religious Jewish science teachers toward the teaching of'controversial'topics in science. Int J Sci Educ. 2010;32:1521-48.

Donnelly LA, Boone WJ. Biology teachers' attitudes toward and use of Indiana's evolution standards. J Res Sci Teach. 2007;44:236-57.

Donnelly L, Akerson V. High school biology students' evolution learning experiences. In: Paper presented at the annual meeting of the national association for research in science teaching, Baltimore, Maryland; 2008. 
Evans EM. The emergence of beliefs about the origins of species in school-age children. Merrill-Palmer Q. 2000;46:221-54.

Evans EM. Cognitive and contextual factors in the emergence of diverse belief systems: creation versus evolution. Cogn Psychol. 2001;42:217-66.

Evans P, Anderson DL. The conceptual inventory of natural selection a decade later: development and pilot testing of a middle school version leads to a revised college/high school version. In: Paper presented at annual meeting of the national association for research in science teaching (NARST), Rio Grande, Puerto Rico; 2013.

Fowler SR, Meisels GG. Florida teachers' attitudes about teaching evolution. Am Biol Teach. 2010;72:96-9.

Fulp SL. Status of elementary school science teaching. Chapel Hill: Horizon Research Inc:; 2002.

Gallup. Americans weigh in on evolution vs. creationism in schools. 2005. http://www.gallup.com/poll/16462/americans-weigh-evolution-vs-creat ionism-schools.aspx. Accessed 10 May 2015.

Gallup. In US, 46\% hold creationist view of human origins. 2014. http://www. gallup.com/poll/170822/believe-creationist-view-human-origins.aspx. Accessed 10 May 2015.

Gerreston H, Bosnick J, Schofield K. A case for content specialists as the elementary classroom teacher. Teach Educ. 2008;43:302-14.

Gess-Newsome J. Delivery models for elementary science instruction: a call for research. Electron J Sci Educ. 1999;3:3.

Glaze AM, Goldston MJ. US teaching and learning of evolution: a critical review of the literature 2000-2014. Sci Educ. 2015;99:500-18.

Graham JM. Congeneric and (essentially) tau-equivalent estimates of score reliability: what they are and how to use them. Educ Psychol Meas. 2006;66:930-44. https://doi.org/10.1177/0013164406288165.

Gregory TR. Understanding natural selection: essential concepts and common misconceptions. Evol Educ Outreach. 2009;2:156-75.

Ha M, Baldwin BC, Nehm RH. The long-term impacts of short-term professional development: science teachers and evolution. Evol Educ Outreach. 2015. https://doi.org/10.1186/s12052-015-0040-9.

Harris PL, Pasquini ES, Duke S, Asscher JJ, Pons F. Germs and angels: the role of testimony in young children's ontology. Dev Sci. 2006;9(1):76-96.

Herrmann PA, French JA, DeHart GB, Rosengren KS. Essentialist reasoning and knowledge effects on biological reasoning in young children. MerrillPalmer Q. 2013;59(2):198-220.

Horowitz P, McIntyre CA, Lord T, O'Dwyer LM, Staudt C. Teaching 'evolution readiness' to fourth graders. Evol Educ Outreach. 2013. https://doi. org/10.1186/1936-6434-6-21.

Johnson RL, Peeples EE. The role of scientific understanding in college: student acceptance of evolution. Am Biol Teach. 1987;49:93-7.

Kahan DM. Climate-science communication and the measurement problem. Adv Political Psychol. 2015;36:1-43.

Keleman D, Emmons NA, Schillaci RS, Ganea PA. Young children can be taught basic natural selection using a picture-storybook intervention. Psychol Sci. 2014;25:893-902.

Kim SY, Nehm RH. A cross-cultural comparison of Korean and American science teachers'views of evolution and the nature of science. Int J Sci Educ. 2011;33(2):197-227.

Levy AJ, Jia Y, Marco-Bujosa L, Gess-Newsome J, Pasquale M. Science specialists or classroom teachers: who should teach elementary science? Sci Educ. 2016;25:10-21.

Lombrozo T, Thanukos A, Weisberg M. The importance of understanding the nature of science for accepting evolution. Evol Educ Outreach. 2008;1:290-8.

Lord T, Marino S. How university students view the theory of evolution. J Coll Sci Teach. 1993:22:353-7.

Losh SC, Nzekwe B. The influence of education major" How diverse preservice teachers view pseudoscience topics. J Sci Educ Technol. 2011;20:570-91.

Mayr E. The growth of biological thought: diversity, evolution and inheritance. Cambridge: Harvard University Press; 1982.

Miller JD, Scott EC, Okamoto S. Public acceptance of evolution. Science. 2006:313:765-6.

Moore R. How well do biology teachers understand the legal issues associated with the teaching of evolution? Bioscience. 2004;54:860-5.

Moore R. Creationism in the biology classroom: what do teachers teach and how do they teach it. Am Biol Teach. 2008;70(2):79-84.

Moore R, Brooks DC, Cotner S. The relation of high school biology courses \& students' religious beliefs to college students' knowledge of evolution. Am Biol Teach. 2011:73:222-6.
Nadelson LS, Nadelson S. K-8 educators perceptions and preparedness for teaching evolution topics. J Sci Teach Educ. 2010;21:843-58.

Nadelson LS, Sinatra GM. Educational professionals' knowledge and acceptance of evolution. Evol Psychol. 2009;7(4):490-516.

National Science Board. Science and engineering indicators 2014. Arlington: National Science Foundation (NSB 14-01); 2014.

Nehm RH, Schonfeld IS. Does increasing biology teacher knowledge of evolution and the nature of science lead to greater preference for the teaching of evolution in schools? J Sci Teach Educ. 2007;18:699-723.

$\mathrm{Nehm} \mathrm{RH}$, Schonfeld IS. Measuring knowledge of natural selection: a comparison of the CINS, an open-response instrument, and an oral interview. J Res Sci Teach. 2008:45:1131-60.

Nehm RH, Kim SY, Sheppard K. Academic preparation in biology and advocacy for teaching evolution: biology versus non-biology teachers. Sci Educ. 2009;93:1122-46.

Pew Research Center. Public and scientists' views on science and society. 2015. http://www.pewinternet.org/2015/01/29/public-and-scientists -views-onscience-and-society/. Accessed 20 Mar 2015.

Prinou L, Halkia L, Skordoulis C. The inability of primary school to introduce children to the theory of biological evolution. Evol Educ Outreach. 2011:4:275-85

Rice JW, Clough MP, Olson JK, Adams DC, Colbert JT. University faculty and their knowledge and acceptance of biological evolution. Evol Educ Outreach. 2015. https://doi.org/10.1186/s12052-015-0036-5.

Rutledge ML, Mitchell MA. High school biology teachers'knowledge structure, acceptance and teaching of evolution. Am Biol Teach. 2002;64:21-8.

Rutledge ML, Sadler KC. Reliability of the measure of acceptance of the theory of evolution (MATE) instrument with university students. Am Biol Teach. 2007:69:332-5.

Rutledge ML, Sadler KC. University students' acceptance of biological theories-is evolution really different? J Coll Sci Teach. 2011:41:38-43.

Rutledge $\mathrm{M}$, Warden $\mathrm{M}$. The development and validation of the measure of the theory of evolution instrument. Sch Sci Math. 1999;99:13-8.

Rutledge M, Warden M. Evolutionary theory, the nature of science and high school biology teachers: critical relationships. Am Biol Teach. 2000;62(1):23-31.

Sager C, editor. Voices of evolution. Berkley: The National Center for Science Education Inc.; 2008

Schwartz RS, Gess-Newsome J. Elementary science specialists: a pilot study of current models and a call for the participation in the research. Sci Educ. 2008;17(2):19-30

Schwartz RS, Abd-El-Khalick F, Lederman NG. Achieving the reform's vision: the effectiveness of a specialist-led elementary science program. Sch Sci Math. 2000;100:181-94.

Shtulman A, Calabi P. Cognitive constraints on understanding and acceptance of evolution. In: Rosengren KS, Brem SK, Evans ME, Sinatra GM, editors. Evolution challenges: Integrating research and practice in teaching and learning about evolution. New York: Oxford University Press; 2012. p. 47-65.

Sinatra GM, Southerland SA, McConaughy F, Demastes J. Intentions and beliefs in students' understanding and acceptance of biological evolution. J Res Sci Teach. 2003;40:510-28.

Smith MU. Current status of research in teaching and learning evolution: I. Philosophical/epistemological issues. Sci Educ. 2010;19:523-38.

Tavakol M, Dennick R. Making sense of Cronbach's alpha. Int J Med Educ. 2011;2:53-5

Trani R. I won't teach evolution; it's against my religion: and now for the rest of the story. Am Biol Teach. 2004;66:419-27.

Wagler A, Wagler R. Addressing the lack of measurement invariance for the measure of acceptance of the theory of evolution. Int I Sci Educ. 2013;35:2278-98

Weiss IR, Banilower ER, McMahon KC, Smith PS. Report of the 2000 national survey of science and mathematics education. Chapel Hill: Horizon Research Inc.; 2001.

Wiles JR. Gifted students' perceptions of their acceptance of evolution, changes in acceptance, and factors involved therein. Evol Educ Outreach. 2014. https://doi.org/10.1186/s12052-014-0004-5. 